\title{
A Study on Employee Engagement in Present Scenario
}

\author{
S.Gousia, S.Sowjanya. \\ Assistant Professor ,Dept of MBA Rajeev Gandhi Memorial College Of Engg\&Tech Nandyal.
}

\begin{abstract}
Employee engagement is the level of commitment and involvement an employee has towards their organization and its values. An engaged employee is aware of business context, and works with colleagues to improve performance within the job for the benefit of the organization. It is a positive attitude held by the employees towards the organization and its values. The paper ocuses on how employee engagement is an antecedent of job involvement and what should company do to make the employees engaged. The paper also looks at the Gallup 12 point questionnaire, welve-question survey that identifies strong feelings of employee engagement and the steps hitch shows how to drive an engaged employee.
\end{abstract}

Keywords: - decision making, goal achievement, intellectual commitment, leadership, motivation, psychology. Sources of Research :Usage of both primary, secondary sourcess.

\section{INTRODUCTION}

Engagement at work was conceptualized by Kahn, (1990) as the 'harnessing of organizational members' selves to their work roles. In engagement, people employ and express themselves physically, cognitively, and emotionally during role performances. The second related construct to engagement in organizational behavior is the notion of flow advanced by Csikszentmihalyi (1975, 1990). Csikzentmihalyi (1975) defines flow as the 'holistic sensation' that, people feel when they act with total involvement. Flow is the state in which there is little distinction between the self and environment. When individuals are in Flow State little conscious control is necessary for their actions. Employee engagement is the thus the level of commitment and involvement an employee has towards their organization and its values. An engaged employee is aware of business context, and works with colleagues to improve performance within the job for the benefit of the organization. The organization must work to develop and nurture engagement, which requires a two-way relationship between employer and employee.' Thus Employee engagement is a barometer that determines the association of a person with the organization

Engagement is most closely associated with the existing construction of job involvement (Brown 1996) and flow (Csikszentmihalyi, 1990). Job involvement is defined as 'the degree to which the job situation is central to the person and his or her identity (Lawler \& Hall, 1970). Kanungo (1982) maintained that job involvement is a 'Cognitive or belief state of Psychological identification. Job involvement is thought to depend on both need saliency and the potential of a job to satisfy these needs. Thus job involvement results form a cognitive judgment about the needs satisfying abilities of the job. Jobs in this view are tied to one's self image. Engagement differs from job in as it is concerned more with how the individual employees his/her self during the performance of his / her job. Furthermore engagement entails the active use of emotions. Finally engagement may be thought of as an antecedent to job involvement in that individuals who experience deep engagement in their roles should come to identify with their jobs.

When Kahn talked about employee engagement he has given important to all three aspects physically, cognitively and emotionally. Whereas in job satisfaction importance has been more given to cognitive side. HR practitioners believe that the engagement challenge has a lot to do with how employee feels about the about work experience and how he or she is treated in the organization. It has a lot to do with emotions which are fundamentally related to drive bottom line success in a company. There will always be people who never give their best efforts no matter how hard HR and line managers try to engage them. "But for the most part employees want to commit to companies because doing so satisfies a powerful and a basic need in connect with and contribute to something significant".

\section{Aspects of Employee Engagement:}

Three basic aspects of employee engagement according to the global studies are:-

$>$ The employees and their own unique psychological makeup and experience

$>$ The employers and their ability to create the conditions that promote employee engagement .

$>$ Interaction between employees at all levels. 
Thus it is largely the organization's responsibility to create an environment and culture conducive to this partnership, and a win-win equation. Categories of Employee Engagement According to the Gallup the Consulting organization there are there are different types of people:-

Engaged--"Engaged" employees are builders. They want to know the desired expectations for their role so they can meet and exceed them. They're naturally curious about their company and their place in it. They perform at consistently high levels. They want to use their talents and strengths at work every day. They work with passion and they drive innovation and move their organization forward.

Not Engaged---Not-engaged employees tend to concentrate on tasks rather than the goals and outcomes they are expected to accomplish. They want to be told what to do just so they can do it and say they have finished. They focus on accomplishing tasks vs. achieving an outcome. Employees who are not-engaged tend to feel their contributions are being overlooked, and their potential is not being tapped. They often feel this way because they don't have productive relationships with their managers or with their coworkers.

Actively Disengaged--The "actively disengaged" employees are the "cave dwellers." They're "Consistently against Virtually Everything." They're not just happy at work; they're busy acting out their unhappiness. They sow seeds of negativity at every opportunity. Every day, actively disengaged workers undermine what their engaged coworkers accomplish. As workers increasingly rely on each other to generate products and services, the problems and tensions that are fostered by actively disengaged workers can cause great damage to an organization's functioning.

\section{Employee Engagement Defined}

\section{Key Metric: Hewitt Engagement Measure}

Engagement is the state of emotional and intellectual commitment to an organization-the degree to which you have captured the hearts and minds of your employees

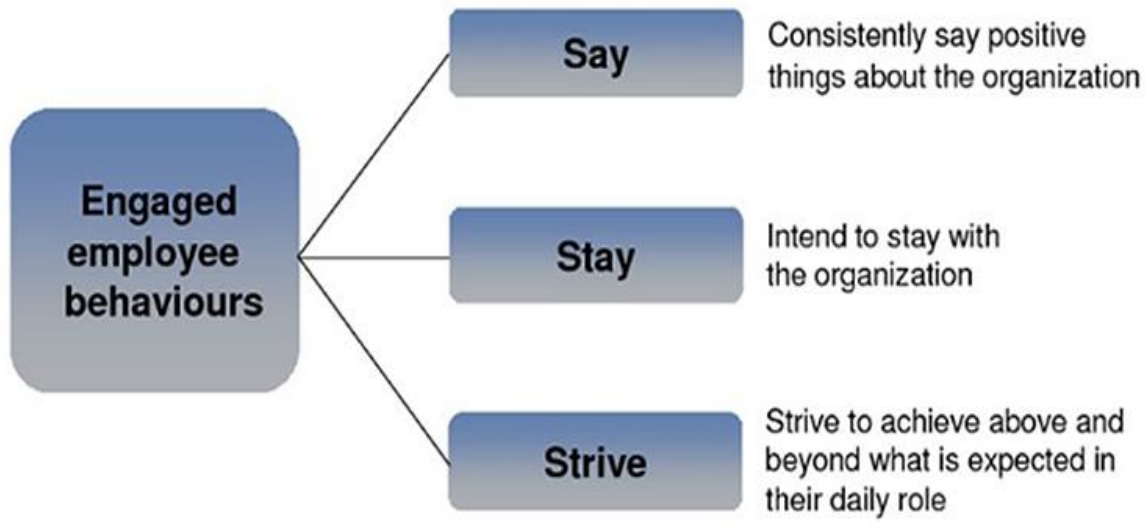

$80 \%$ of employees are engaged at a typical Best Employer

CBSR and Hewitt Associates, "Engaging Employees Through CSR" webinar, Jan 2010

\section{IMPORTANCE OF ENGAGEMENT}

Engagement is important for managers to cultivate given that disengagement or alienation is central to the problem of workers' lack of commitment and motivation (Aktouf). Meaningless work is often associated with apathy and detachment from ones works (Thomas and Velthouse). In such conditions, individuals are thought to be estranged from their selves (Seeman, 1972) .Other Research using a different resource of engagement (involvement and enthusiasm) has linked it to such variables as employee turnover, customer satisfaction - loyalty, safety and to a lesser degree, productivity and profitability criteria (Harter, Schnidt \& Hayes, 2002) 
An organization's capacity to manage employee engagement is closely related to its

ability to achieve high performance levels and superior business results. Some of the advantages of Engaged employees are - Engaged employees will stay with the company, be an advocate of the company and its products and services, and contribute to bottom line business success.

$>$ They will normally perform better and are more motivated.

$>$ There is a significant link between employee engagement and profitability.

$>$ They form an emotional connection with the company. This impacts their attitude towards the company's clients, and thereby improves customer satisfaction and service levels

$>$ It builds passion, commitment and alignment with the organization's strategies and goals

$>$ Increases employees' trust in the organization

$>$ Creates a sense of loyalty in a competitive environment

$>$ Provides a high-energy working environment

$>$ Boosts business growth

$>$ Makes the employees effective brand ambassadors for the company

A highly engaged employee will consistently deliver beyond expectations. In the workplace research on employee engagement (Harter, Schmidt \& Hayes, 2002) have repeatedly asked employees 'whether they have the opportunity to do what they do best everyday'. While one in five employees strongly agree with this statement. Those work units scoring higher on this perception have substantially higher performance. Thus employee engagement is critical to any organization that seeks to retain valued employees. The Watson Wyatt consulting companies has been proved that there is an intrinsic link between employee engagement, customer loyalty, and profitability. As organizations globalize and become more dependent on technology in a virtual working environment, there is a greater need to connect and engage with employees to provide them with an organizational 'identity.'

\section{Some example images of employee engagement:}

\section{Example:1}
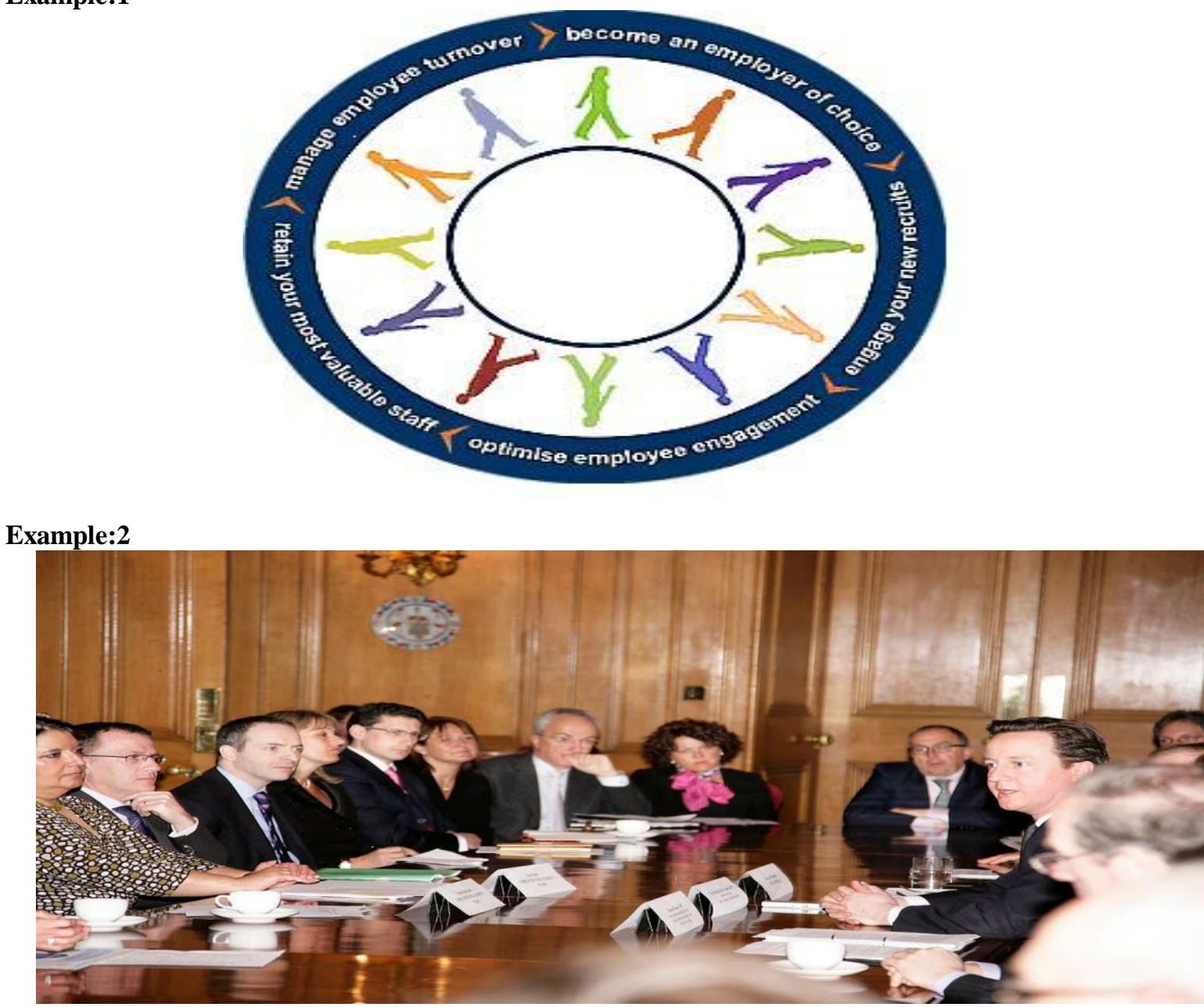
Factors Leading to Employee Engagement:

Studies have shown that there are some critical factors which lead to Employeeengagement. Some of them identified are

- Career Development- Opportunities for Personal Development:

Organizations with high levels of engagement provide employees with opportunities to develop their abilities, learn new skills, acquire new knowledge and realize their potential. When companies plan for the career paths of their employees and invest in them in this way their people invest in them.

- Career Development- Effective Management of Talent:

Career development influences engagement for employees and retaining the most talented employees and providing opportunities for personal development.

- Leadership- Clarity of Company Values :

Employees need to feel that the core values for which their companies stand are unambiguous and clear.

- Leadership - Respectful Treatment of Employees:

Successful organizations show respect for each employee's qualities and contribution -regardless of their job level.

- Leadership - Company's Standards of Ethical Behaviour:

A company's ethical standards also lead to engagement of an individual.

- Empowerment:

Employees want to be involved in decisions that affect their work. The leaders of high engagement workplaces create a trustful and challenging environment, in which employees are encouraged to dissent from the prevailing orthodoxy and to input and innovate to move the organization forward.

- Image :

How much employees are prepared to endorse the products and services which their company provides its customers depends largely on their perceptions of the quality of those goods and services. High levels of employee engagement are inextricably linked with high levels of customer engagement.

\section{Other factors:}

\section{* Equal Opportunities and Fair Treatment:}

The employee engagement levels would be high if their bosses (superiors) provide equal opportunities for growth and advancement to all the employees.

* Performance appraisal:

Fair evaluation of an employee's performance is an important criterion for determining the level of employee engagement. The company which follows an appropriate performance appraisal technique (which is transparent and not biased) will have high levels of employee engagement.

* Pay and Benefits:

The company should have a proper pay system so that the employees are motivated to work in the organization. In order to boost his engagement levels the employees should also be provided with certain benefits and compensations.

\section{* Health and Safety:}

Research indicates that the engagement levels are low if the employee does not feel secure while working. Therefore every organization should adopt appropriate methods and systems for the health and safety of their employees.

\section{* Job Satisfaction:}

Only a satisfied employee can become an engaged employee. Therefore it is very essential for an organization to see to it that the job given to the employee matches his career goals which will make him enjoy his work and he would ultimately be satisfied with his job.

\section{* Communication:}

The company should follow the open door policy. There should be both upward and downward communication with the use of appropriate communication channels in the organization. If the employee is given a say in the decision making and has the right to be heard by his boss than the engagement levels are likely to be high.

\section{* Family Friendliness:}

A person's family life influences his wok life. When an employee realizes that the organization is considering his family's benefits also, he will have an emotional attachment with the organization which leads to engagement.

\section{* Co-operation:}

If the entire organization works together by helping each other i.e. all the employees as well as the supervisors co-ordinate well than the employees will be engaged. 


\section{How to measure Employee Engagement?}

Gallup research consistently confirms that engaged work places compared with least engaged are much more likely to have lower employee turnover, higher than average customer loyalty, above average productivity and earnings. These are all good things that prove that engaging and involving employees make good business sense and building shareholder value. Negative workplace relationships may be a big part of why so many employees are not engaged with their jobs.

\section{Step I: Listen}

The employer must listen to his employees and remember that this is a continuous process. The information employee's supply will provide direction. This is the only way to identify their specific concerns. When leaders listen, employees respond by becoming more engaged. This results in increased productivity and employee retention. Engaged employees are much more likely to be satisfied in their positions, remain with the company, be promoted, and strive for higher levels of performance.

\section{Step II: Measure current level of employee engagement}

Employee engagement needs to be measured at regular intervals in order to track its contribution to the success of the organization.But measuring the engagement (feedback through surveys) without planning how to handle the result can lead employees to disengage. It is therefore not enough to feel the pulse - the action plan is just as essential.

\section{Knowing the Degree in which Employees Are Engaged?}

Employee engagement satisfaction surveys determine the current level of employee engagement. A well-administered satisfaction survey will let us know at what level of engagement the employees are operating. Customizable employee surveys will provide with a starting point towards the efforts to optimize employee engagement. The key to successful employee satisfaction surveys is to pay close attention to the feedback from the staff. It is important that employee engagement is not viewed as a onetime action. Employee engagement should be a continuous process of measuring, analyzing, defining and implementing.

The employee survey is a diagnostic tool of choice in the battle for the hearts of employees. Studies of Gallup, Mercer, Hewitt and Watson Wyatt (consulting companies) asked workers number of questions relating to their job satisfaction. Gallup being one of oldest the consulting organization fin conducting engagement survey\} creates a feedback system for employers that would identify and measure elements of worker engagement most tide to the bottom line. Things such as sales, growth, productivity and customer loyalty are all accessed.

After Hundreds of focus group and thousands of interviews with employees in a variety of industries, Gallup came up with Q. 12, a twelve-question survey that identifies strong feelings of employee engagement. They have identified 12 questions that most effectively measure the links (the Gallup Q12).

1. Do you know what is expected of you at work?

2. Do you have the materials and equipment you need to do your work right?

3. At work, do you have the opportunity to do what you do best every day?

4. In the last seven days, have you received recognition or praise for doing good work?

5. Does your supervisor, or someone at work, seems to care about you as a person?

6. Is there someone at work who encourages your development?

7. At work, do your opinions seem to count?

8. Does the mission/purpose of your company make you feel your job is important?

9. Are your associates (fellow employees) committed to doing quality work?

10. Do you have a best friend at work?

11. In the last six months, has someone at work talked to you about your progress?

12. In the last year, have you had opportunities at work to learn and grow?

\section{Some of the discussions which come from Gallup's questions are:-}

Know what is expected of me at work- employees should know exactly what is expected of them. If expectations are unclear, employees will inevitably face frustration, and will be open for other opportunities where they do know what's expected of them, and where their contributions are measured and recognized. Materials and equipment- Employees need the right tools and equipment to support their skills, experience and talents \& perform their jobs at an optimum level. Do what I do best every day - Are your employees cast in the right roles? Knowing the critical demands for every role is a key to ensuring that talents fit those demands.

Supervisor/Someone at work cares -Managers must spend most of their time with their most productive talent. Many managers give their greatest degree of attention to employees who are falling behind. Talented, 
productive people crave time and attention from their managers, and will leave your company if they have a weak relationship (or no relationship) with their manager or supervisor.

Co-workers committed to quality.-Many companies arbitrarily put teams together without considering that employees only psychologically commit to teams if they perceive their team members will support their high level of commitment and performance. Talented employees set high standards and depend upon those around them to support their growth toward excellence.

Opportunities to learn and grow- The Company should create an environment that encourages employees to drive towards innovation or to create better systems for more productive results. Great managers always ask what skills and knowledge need to accompany talent to result in the greatest outcome for each

As discussed the Gallup study Q12 is based on positive Psychology and emotions. Having a best friend at work or receiving recognition every week makes you feel cared for and proud respectively. If you want to keep recreating those positive emotions, then you keep coming back to work.

So the Q. 12 measures engagement, and engagement is a positive emotional connection to the work. Thus the mechanism of the broaden- and - build theories and the action tendencies of positive emotions help in understanding why the Q. 12 has been so powerful for Gallup in terms of predicting outcomes. Borden - and Build theory is about evolutionary significance of positive emotions. Positive emotions are better observed over the long haul. Their effects accumulate and compound overtime and the adaptive benefits are evident from later, when people face new challenges. The Gallup research has thus made a contribution in adding an additional ' $\mathrm{P}$ ' to the 4 P's of marketing i.e. product, price, and promotion place and now people to the mix. In the combination of 14engaged employees, Gallup brings engaged customers to form the concept of human sigma. These include customer engagement, loyalty and emotional attachment. Customer

engagement hierarchy, customer engagement scores and developing the culture of engagement and customer focus. The Gallup Organization decided to initiate a multi-year research project to try and define a great workplace - a great workplace was one where employees were satisfied with their jobs and this thus helps to produce positive business outcomes.

According to the study of Watson Wyatt, the service - profit chain establishes relationship between profitability, customer loyalty and employee satisfaction, loyalty and productivity. The links in the chain (which should be regarded as propositions) are as follows: profit and growth are stimulated primarily by customer loyalty. Loyalty is a direct result of customer's satisfaction. Satisfaction is largely influenced by the services provided to customers. Satisfied, loyal and productive employees create value. Employee's satisfaction inturn results primary ly from high quality support services and policies that enable employees to deliver results to customers. While many organizations are beginning to measure relationship between individual links in the service only a few have related the links in the meaningful ways that can lead to comprehensive strategies for achieving lasting competitive advantage of building employee engagement. In a study of its seven telephone customer service centers (MCI found that there is a clear relationship between employee's perceptions of the quality of services and employee engagement.

\section{Step II1: - Identify the problem areas}

Identify the problem areas to see which are the exact areas, which lead to disengaged employees

\section{Step IV: Taking action to improve employee engagement by acting upon the problem areas}

Nothing is more discouraging to employees than to be asked for their feedback and see no movement toward resolution of their issues. Even the smallest actions taken to address concerns will let the staff know how their input is valued. Feeling valued will boost morale, motivate and encourage future input. Taking action starts with listening to employee feedback and a definitive action plan will need to be put in place finally.

\section{CONCLUSION}

Employee Engagement is the buzz word term for employee communication. It is a positive attitude held by the employees towards the organization and its values. It is rapidly gaining popularity, use and importance in the workplace and impacts organizations in many ways. Employee engagement emphasizes the importance of employee communication on the success of a business. An organization should thus recognize employees, more than any other variable, as powerful contributors to a company's competitive position. Therefore employee engagement should be a continuous process of learning, improvement, measurement and action.We would hence conclude that raising and maintaining employee engagement lies in the hands of an organization and requires a perfect blend of time, effort, commitment and investment to craft a successful endeavor 